Original

\title{
Effect of commercial ethanol propolis extract on the in vitro growth of Candida albicans collected from HIV-seropositive and HIV-seronegative Brazilian patients with oral candidiasis
}

\author{
Rachel S. Martins ${ }^{\S}$, Erika S. J. Péreira ${ }^{\S}$, Sérgio M. Lima Jr. ${ }^{\S}$, Maria I. B. Senna ${ }^{\S}$, \\ Ricardo A. Mesquita ${ }^{\dagger}$ and Vagner R. Santos ${ }^{\ddagger}$

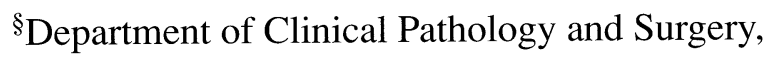 \\ ${ }^{\dagger}$ Department of Clinical Pathology and Surgery, Laboratory of Oral Pathology, \\ ‡Department of Oral Pathology, Laboratory of Microbiology, \\ School of Dentistry, Minas Gerais Federal University, Belo Horizonte, Brazil
}

(Received 26 June 2001 and accepted 27 March 2002)

\begin{abstract}
The present study assessed the susceptibility of Candida albicans strains, collected from HIV-positive patients with oral candidiasis, to a commercial $20 \%$ ethanol propolis extract (EPE) and compare it to the inhibitory action of the standardized antifungal agents nystatin (NYS), clotrimazole (CL), econazole (EC), and fluconazole (FL). Twelve C. albicans strains collected from HIV-positive patients with oral candidiasis were tested. The inhibition zones were measured with a pachimeter and the results are reported as means and standard deviation $(M \pm S D)$. Data were analyzed statistically by the non-parametric Kruskal-Wallis test. EPE inhibited all the $C$. albicans strained tested. No significant difference was observed between the results obtained with NYS and EPE, while significant differences were observed between EPE and other antifungals. The $C$. albicans strains tested showed resistance to the remaining antifungal agents. The propolis extract used in this study inhibited the in vitro growth of $C$. albicans collected from HIVseropositive Brazilian patients, creating/forming
\end{abstract}

Correspondence to Dr. Vagner Rodrigues Santos, Laboratório de Microbiologia, Faculdade de Odontologia, UFMG, Campus da Pampulha. Av. Presidente Antonio Carlos 6627, Belo Horizonte, Minas Gerais, CEP 31.270-901, Brazil Tel: +55-031 466-1283/+55-031-3499-2497

Fax: +55-031-3499-2430/+55-031- 466-1283

E-mail address: santo@mail.odonto.ufmg.br inhibition zones like those ones formed by NYS. This fact suggests that commercial EPE could be an alternative medicine in the treatment of candidiasis from HIV-positive patients. However, in vivo studies of the effect of EPE are needed to determine its possible effects on the oral mucosa. (J. Oral Sci. 44, 41-48, 2002)

Key words: oral candidiasis; Candida albicans; HIV patients; Brazilian propolis.

\section{Introduction}

Opportunistic infections caused by Candida species are particularly common in immunocompromised patients (1). It is known that more than $90 \%$ of Human Immunodeficiency Virus- infected patients (HIV- positive patients) suffer from oral candidiasis at some point during their disease $(2,3)$.

Many antifungal agents are available for the treatment of candidiasis, such as polyenes, azoles and the DNAanalogue 5-fluorocytosine. Despite the availability of such an array of agents, failure of therapy is not uncommon $(4,5)$. Different studies have suggested the resistance of some $C$. albicans strains from HIV-positive patients to antifungal agents (6-9). Propolis is a resinous hive product collected by bee from tree buds and mixed with secreted beeswax. The propolis is used by bees as a glue to seal the opening of the hives (10), and thus being considered a natural 
antibiotic (11). Propolis has been used as a therapeutic agent by the world population since the time of Hippocrates (12). It is known that the ethanolic extract of propolis (EPE) exhibits some pharmacological activities, such as antibacterial, antiviral, antifungal, anti-inflammatory, anesthetic and cytostatic properties (13-15). A number of investigations have shown the antimicrobial activity of propolis against various pathogenic microorganisms $(10,16,17)$. Furthermore, earlier reports demonstrated that the EPE inhibited the in vitro growth of Candida albicans (18-20).

Therefore, pharmacological applications of propolis preparations have led to an increased interest in its chemical composition. So far, polyphenolic compounds, e.g. flavonoid aglycones, phenolic acids and their esters, and phenolic aldehydes, have been mainly identified in propolis collected by bees in different regions (21). The flavonoid aglycones have been considered the main active substance in propolis. However, the composition of propolis is quantitatively and qualitatively variable, depending on area and ecology $(10,20,22,23)$.

The composition of propolis can affect their biological activity. Considering that in Brazil the EPE is not recognized as a medicine, the access of population is made easy by the low price of the product in market and this same population uses it discriminated, the aim of the present paper was to evaluate the susceptibility of Candida albicans from HIV-positive patients with oral candidiasis to a commercial 20\% (EPE) and compare it to the inhibitory action of some popular antifungal agents.

\section{Materials and Methods \\ Microorganism strains}

Candida albicans strains were collected from oral lesions of pseudomembranous and erythematous candidiasis of 12 HIV-positive patients seen at the Reference Center Treatment for Sexually Transmitted Diseases of Belo Horizonte, Minas Gerais State (PR1, PR2, PR3, PR4, PR5, PR6, PR7, PR8, PR9, PR10, PR11 and PR12). Twelve patients, eight male and four female, with ages ranging from 22 to 46 years $($ mean $=31.1$ ), were selected. The strains were isolated in Sabouraud broth (Difco, USA) containing chloramphenicol and incubated at $37^{\circ} \mathrm{C}$ for 48 hours and identified by colony morphology, germinative tubes formation, and biochemically (Candifast, Microbio, France). Candida albicans was collected from 12 normal soronegative patients (PN1, PN2, PN3, PN4, PN5, PN6, PN7, PN8, PN9, PN10, PN11 and PN12), six male and six female, with ages ranging from 26 to 48 years (mean $=34.7$ ) with erythematous atrofic candidiasis (Denture stomatitis).

\section{Propolis solutions}

Ethanol extract containing 20\% propolis (EPE) (Nectar Farmacêutica, Belo Horizonte, MG, Brazil) was purchased at random in stores specialized in apicultural products in Belo Borizonte (Minas Gerais State, South-Eastern Brazil) and tested for their inhibitory ability for the microorganism growth in vitro. The original formula of the propolis solution obtained commercially was used in the experiments.

\section{Test of antimicrobial susceptibility (agar diffusion test)}

The susceptibility test of $C$. albicans to the propolis solution was performed by agar diffusion according to the method of Collins et al. (24). A $0.1 \mathrm{ml}$ aliquot of 48 hour cultures of each 12 Candida strains incubated at $37^{\circ} \mathrm{C}$ in dextrose Sabouraud, corresponding to 0.5 turbidity on the McFarland scale $\left(10^{8} \mathrm{UFC} / \mathrm{ml}\right)$, was plated onto $30 \mathrm{ml}$ agar Sabouraud (Difco, USA) previously melted and distributed on Petri dishes measuring $150 \mathrm{~mm}$ in diameter.

Sterile blank disks (CECON, São Paulo, Brazil) were soaked in $20 \mu$ lof the ethanol propolis solution (20\%) and applied to the agar surface previously seeded with the microorganism. Econazole (EC, $25 \mathrm{mg}$ ), clotrimazole (CL, $50 \mathrm{mg}$ ), and fluconazole (FL, $25 \mathrm{mg}$ ) (CECON, São Paulo, Brazil) discs were used to compare the effect of the EPE. Positive and negative controls of the discs containing 100 IU nystatin (NYS) (CECON, Sao Paulo, Brazil) and $20 \mu \mathrm{l}$ sterile distilled water (DW) were used, respectively. The effect of $93.2^{\circ}$ alcohol (AL) was also determined, because it is the solvent in the EPE.

After 48 hours of incubation at $37^{\circ} \mathrm{C}$, the diameters of the inhibition zones were measured and compared according to the method of Hindler and Jorgensen (25). For each Candida sample, three experiments were made in three different times.

\section{Statistical analysis}

The results of the diameters of the inhibition zones are reported as means \pm standard deviation $(\mathrm{M} \pm \mathrm{SD})$ and were analyzed statistically by the non-parametric KruskalWallis test. Differences at the $1 \%$ level of variation $(P<$ $0.05)$ were considered to be significant.

\section{Results}

EPE was effective in inhibiting the in vitro growth of all C. albicans strains tested (Fig. 1). The mean values of the inhibition zones of C. albicans isolates from 12 HIVpositive and $12 \mathrm{HIV}$-negative patients exposed to different substance are shown in Table 1 and Table 2, respectively. 
There were no significant differences between the data obtained for EPE and NYS $(P<0.05)$. However, there was significant difference between NYS and other antifungal agents. Strains PR9 and PR11 of C. albicans were significantly more susceptible to EPE than NYS. The mean diameters of the inhibition zones caused by EPE and NYS were similar for strains PR3, PR6, PR7 and PR8.

EC showed significantly lower inhibition zones for 10 of the 12 C. albicans strains tested when compared to EPE and NYS. EC was ineffective against in vitro growth of strains PR2, PR8 and PR11. CL and FL did not inhibit the in vitro growth of the 12 C. albicans strains tested. Double inhibition zone areas were observed around the discs, showing microorganism resistance to these antifungal agents (Fig. 1).

However, all the strains of C. albicans collected from HIV-seronegative patients with Denture stomatitis showed significant susceptibility to all antifungals and EPE tested. When compared to EC, CL and FL, the inhibition zones were bigger and were significantly different from those seen with NYS and EPE. The inhibition zones included by AL were significantly smaller than those observed for all antifungal agents tested, included EPE.

\section{Discussion}

This paper studied the in vitro susceptibility of $C$. albicans to one $20 \%$ commercial brand ethanol extract of Brazilian propolis. The sample was used as it is presented

Table 1 Mean* and Standard Deviation $(\mathrm{M} \pm \mathrm{SD})$ inhibition zones values of in vitro susceptibility of Candida albicans from HIV-seropositive patients exposed at commercial EPE, antifungal agents and 93.2 ${ }^{\circ}$ alcohol

\begin{tabular}{crrrrrc}
\hline Isolate & EPE $20 \%$ & \multicolumn{1}{c}{ EC } & \multicolumn{1}{c}{ NYS } & \multicolumn{1}{c}{ AL } & \multicolumn{1}{c}{ CL } & FL \\
\hline PR1 & $17.6 \pm 1.52$ & $3.3 \pm 5.77$ & $17.0 \pm 1.00$ & $10.3 \pm 1.15$ & $0.00 \pm 0.00$ & $0.00 \pm 0.00$ \\
PR2 & $21.3 \pm 4.10$ & $0.0 \pm 0.00$ & $15.3 \pm 1.15$ & $11.2 \pm 2.00$ & $0.00 \pm 0.00$ & $0.00 \pm 0.00$ \\
PR3 & $16.6 \pm 0.50$ & $6.6 \pm 5.77$ & $17.0 \pm 1.00$ & $6.0 \pm 5.10$ & $0.00 \pm 0.00$ & $0.00 \pm 0.00$ \\
PR4 & $16.3 \pm 2.30$ & $10.6 \pm 1.15$ & $17.6 \pm 1.15$ & $5.30 \pm 4.60$ & $0.00 \pm 0.00$ & $0.00 \pm 0.00$ \\
PR5 & $20.3 \pm 2.51$ & $3.3 \pm 5.77$ & $16.6 \pm 0.57$ & $10.3 \pm 1.15$ & $0.00 \pm 0.00$ & $0.00 \pm 0.00$ \\
PR6 & $18.6 \pm 1.50$ & $6.6 \pm 5.77$ & $17.0 \pm 1.77$ & $9.5 \pm 1.15$ & $0.00 \pm 0.00$ & $0.00 \pm 0.00$ \\
PR7 & $17.3 \pm 050$ & $7.3 \pm 6.83$ & $18.0 \pm 1.00$ & $9.5 \pm 1.15$ & $0.00 \pm 0.00$ & $0.00 \pm 0.00$ \\
PR8 & $16.6 \pm 3.50$ & $0.0 \pm 0.00$ & $15.3 \pm 0.50$ & $9.5 \pm 1.15$ & $0.00 \pm 0.00$ & $0.00 \pm 0.00$ \\
PR9 & $29.6 \pm 0.50$ & $7.3 \pm 6.40$ & $20.0 \pm 0.00$ & $9.0 \pm 0.00$ & $0.00 \pm 0.00$ & $0.00 \pm 0.00$ \\
PR10 & $23.0 \pm 2.80$ & $3.3 \pm 5.77$ & $18.0 \pm 1.77$ & $11.0 \pm 0.00$ & $0.00 \pm 0.00$ & $0.00 \pm 0.00$ \\
PR11 & $25.6 \pm 1.15$ & $0.0 \pm 0.00$ & $17.0 \pm 0.00$ & $11.6 \pm 1.15$ & $0.00 \pm 0.00$ & $0.00 \pm 0.00$ \\
PR12 & $20.0 \pm 0.00$ & $3.3 \pm 5.77$ & $20.0 \pm 0.00$ & $9.0 \pm 0.00$ & $0.00 \pm 0.00$ & $0.00 \pm 0.00$ \\
\hline
\end{tabular}

Legend: $\mathrm{EPE}=$ Ethanol Propolis Extract; EC = econazole; $\mathrm{NYS}=$ nystatin; $\mathrm{AL}=$ alcohol;

$\mathrm{CL}=$ clotrimazole $; \mathrm{FL}=$ fluconazole

${ }^{*}$ Mean of three measurements

Table 2 Mean* and Standard Deviation $(\mathrm{M} \pm \mathrm{SD})$ inhibition zones values of in vitro susceptibility of Candida albicans from HIV-seronegative patients exposed at commercial EPE, antifungal agents and $93.2^{\circ}$ alcohol

\begin{tabular}{cccrrrc}
\hline Isolate & EPE $20 \%$ & EC & \multicolumn{1}{c}{ NYS } & \multicolumn{1}{c}{ AL } & CL & FL \\
\hline PN1 & $19.0 \pm 1.73$ & $27.1 \pm 2.60$ & $18.0 \pm 0.00$ & $10.3 \pm 1.15$ & $25.6 \pm 2.08$ & $22.6 \pm 1.15$ \\
PN2 & $17.3 \pm 2.80$ & $26.0 \pm 1.00$ & $17.0 \pm 1.73$ & $11.2 \pm 2.00$ & $24.6 \pm 0.50$ & $23.3 \pm 1.15$ \\
PN3 & $21.0 \pm 1.73$ & $27.6 \pm 2.08$ & $18.0 \pm 0.00$ & $6.0 \pm 5.10$ & $25.6 \pm 0.57$ & $24.00 \pm 0.00$ \\
PN4 & $21.0 \pm 1.00$ & $25.6 \pm 0.50$ & $18.0 \pm 0.00$ & $5.30 \pm 4.60$ & $25.3 \pm 1.50$ & $22.6 \pm 1.15$ \\
PN5 & $20.3 \pm 1.15$ & $25.0 \pm 0.00$ & $18.0 \pm 0.00$ & $10.3 \pm 1.15$ & $25.3 \pm 0.50$ & $22.3 \pm 0.50$ \\
PN6 & $18.3 \pm 0.50$ & $25.6 \pm 0.50$ & $17.3 \pm 1.15$ & $9.5 \pm 1.15$ & $25.3 \pm 0.50$ & $22.3 \pm 0.50$ \\
PN7 & $19.6 \pm 1.50$ & $26.3 \pm 0.50$ & $17.6 \pm 0.57$ & $9.5 \pm 1.15$ & $25.3 \pm 0.50$ & $24.0 \pm 0.00$ \\
PN8 & $20.6 \pm 0.50$ & $25.6 \pm 1.15$ & $18.0 \pm 0.00$ & $9.5 \pm 1.15$ & $25.3 \pm 1.15$ & $22.3 \pm 0.50$ \\
PN9 & $19.0 \pm 1.70$ & $26.0 \pm 0.00$ & $18.0 \pm 1.00$ & $9.0 \pm 0.00$ & $25.0 \pm 0.00$ & $22.6 \pm 1.15$ \\
PN10 & $20.3 \pm 1.15$ & $25.6 \pm 0.50$ & $18.0 \pm 0.00$ & $11.0 \pm 0.00$ & $25.0 \pm 1.00$ & $22.0 \pm 0.00$ \\
PN11 & $19.6 \pm 1.50$ & $25.6 \pm 0.50$ & $18.0 \pm 0.00$ & $11.6 \pm 1.15$ & $25.0 \pm 0.00$ & $23.0 \pm 1.00$ \\
PN12 & $17.0 \pm 1.15$ & $25.6 \pm 0.50$ & $18.6 \pm 1.15$ & $9.0 \pm 0.00$ & $25.6 \pm 0.50$ & $23.3 \pm 1.15$ \\
\hline
\end{tabular}

Legend: $\mathrm{EPE}=$ Ethanol Propolis Extract $\mathrm{EC}=$ econazole; $\mathrm{NYS}=$ nystatin; $\mathrm{AL}=$ alcohol;

$\mathrm{CL}=$ clotrimazole; $\mathrm{FL}=$ fluconazole

${ }^{*}$ Mean of three measurements 
to the population, without modifications.

The chemical compounds of propolis have been isolated and analyzed in different countries, with caffeic acid, coumaric acid and flavonoid aglycones possibly accounting for the antibiotic power of this resin (26). The chemical constitution of propolis varies according to the type of bee, the geographic area of origin and the extraction and quality control methods used by each manufacturer (7). Chemometrics has been shown quite efficient in uncovering relationships between chemical composition of a sample and its geographical origin. Forty propolis samples originating from the South and South East of Brazil were analyzed by high performance liguid chromatography (HPLC) and 18 compounds of interest were studied which included: caffeic, p- coumaric and ferulic acids, and some of their derivatives, pinobanksin, a derivative of kaempferol and five phenolic compounds (assigned as 3-prenyl4hydroxycinnamic acid (PHCA); 2,2-dimethyl-6carboxyethnyl-2H-1-benzopyran (DCBEN); 3,5-diprenyl4-hydroxycinnamic acid (DHCA); compound E (still unknown) and 6-propenoic-2,2-dimethyl-8-prenyl-2H-1benzopyran acid (DPB). Principal Component Analysis (PCA) indicated three different groups of propolis samples, having the same typical chromatogram, evaluated by HPLC. Samples from the South East group were rich in derivatives of kaempferol. Samples from the South group had a high content of DPB compound, but a low concentration of kaempferol derivatives and of DCBE compound. Samples from the South group II were

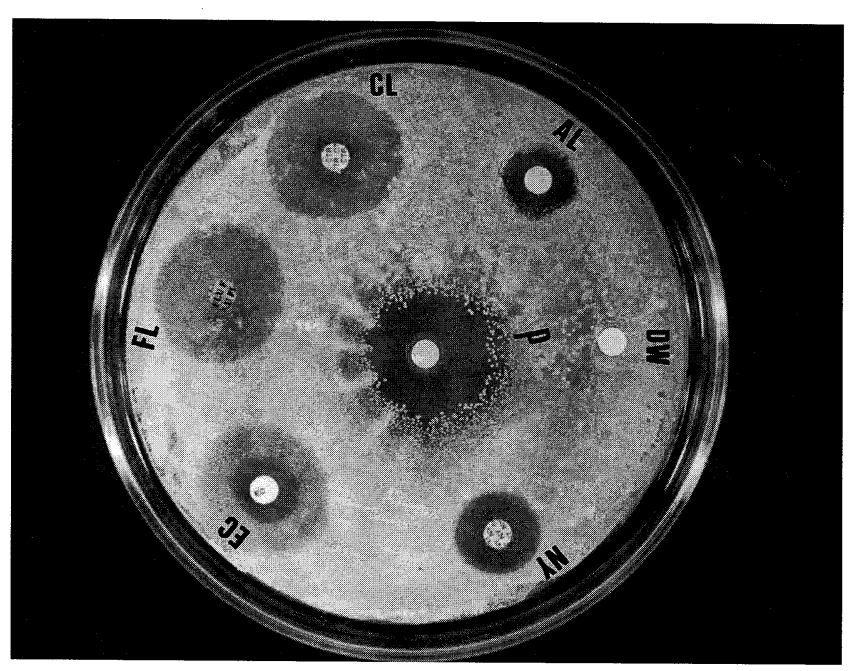

Fig. 1 Inhibition zones of in vitro culture of Candida albicans collected from HIV-positive patients exposed to Ethanol Extract Propolis (EPE), and antifungal agents.

$\mathrm{P}=$ Ethanol Propolis Extract, EC = econazole, NYS = nystatin, $\mathrm{AL}=$ alcohol, $\mathrm{CL}=$ clotrimazole, $\mathrm{FL}=$ fluconazole, $\mathrm{DW}=$ distilled water characterized by a high concentration of DCBEN, DHCA, p-coumaric and DPB compounds.

Therefore, the identification of new compounds in Brazilian propolis can give useful information about the plant sources of a given geographic area (27).

Several studies have demonstrated the antimycotic effect of propolis $(11,28)$. Velikova et al. (29) tested twenty-one propolis samples produced by 12 different Meliponinae species which were analyzed by GC-MS. Several chemical types of stingless bees' propolis could be grouped, according to the prevailing type of compounds like: "gallic acid," "diterpenic" and "triterpenic" types. The results confirm that neither the bee species nor the geographical location determine the chemical composition of Meliponinae propolis and the choice of its plant source, respectively. This could be explained by the fact that Meliponinae forage over short distances (maximum 500 $\mathrm{m}$ ) and thus use as propolis source the first plant exudate they found during their flights. The antibacterial, antifungal and cytotoxic activities of the samples were also investigated. Most samples had weak or no activity against E. coli, and weak action against Candida albicans. Some of them showed significant activity against $S$. aureus, presumably connected to the high concentration of diterpenic acids.

Several investigators have demonstrated the antifungal action of propolis against C.albicans $(12,30)$, but few workers have documented the effect of the antifungal activity of Brazilian propolis on in vitro growth of $C$. albicans of HIV-seropositive Brazilian patients. The mean inhibition zones caused by the positive control (NYS) in all Candida species tested corresponded to the pattern previously defined in the literature $(4,31)$. The $C$. albicans resistance to $\mathrm{EC}, \mathrm{CL}$ and FL observed in this work is explained by the fact that the HIV-positive patients have already been treated with these antifungal agents. The zones of inhibition induced by EPE were similar to those observed for NYS, with no significant difference in HIVpositive C.albicans inhibition. However, the EPE mechanism of action on C.albicans needs more studies. The mechanism of the antimicrobial action of propolis seems to be complex and is not completely understood. According to Amoros et al. (32) and Bonhevi et al. (17), its activity against microorganisms is more related to the synergistic effect of flavonoids (and other phenolics) than to the individual compounds. These findings are in agreement with those of Takaisikikuni and Schilcher (33), who observed that the antibacterial action against Strep. agalactiae was complex, involving several mechanisms such as the formation of pseudomulticellular streptococci; disorganization of the cytoplasm, the cytoplasmatic 
membrane, and the cell wall, partial bacteriolysis; and inhibition of protein synthesis. They concluded that a simple analogy cannot be made with the mode of action of any classic antibiotics.

Marcucci et al. (34) isolated four compounds from Brazilian propolis. The authors identified them as: 1) 3prenyl-4-hydroxycinnamic acid (PHCA), 2) 2,2-dimethyl6- carboxyethenyl-2H-1-benzopyrane (DCBEN), 3) 3,5diprenyl-4-hydroxycinnamic acid (DHCA), and 4) 2,2dimethyl-6-carboxyethenyl-8-prenyl-2H-1-benzopyran (DPB). The structures of the compounds were determined by MS and NMR techniques. All compounds were assayed against Trypanosoma cruzi and the bacteria Escherichia coli, Pseudomonas aeruginosa, Staphylococcus aureus and Streptococcus faecalis. Compounds (1) to (4) were active against T.cruzi. With the exception of (1), all compounds presented activity against the bacteria tested. However, the mechanism of action of propolis was not known until now.

De Paula et al. (35) demonstrated that 7 of the 14 Brazilian brands of ethanol extract solutions of propolis tested presented a pattern of inhibition similar to NYS against the "in vitro" growth of $C$. albicans. The author previously demonstrated that EPE induced zones of inhibition varied according to different $C$. albicans strains. The variations observed in the diameter of inhibition zones around the discs containing propolis were probably related to the type and concentration of chemical components, and also to bee species and to the geographic region where they were produced $(10,12,27,29,36-38)$.

Propolis is a resinous hive product collected by honeybees from various plant sources. The composition of the propolis depends upon the time, vegetation and the area of collection. Thus, quality evaluation of the propolis is important, before use in food and beverages. For this propose, methanol and water extracts of six different propolis from Brazil were studied by chromatography (39). The authors (39) demonstrated 39 compounds with high intensity variety between B1-M/ B1-W and B6-M/ $\mathrm{B} 6-\mathrm{W}$ propolis. In this study, the B5-M propolis sample represent the EPE of our experiment.

All experiments present samples of microorganism resistance to $93.2^{\mathrm{o}}$ alcohol as shown in figure 1 , a finding not observed with EPE. In our experiments, we used $20 \%$ EPE as a pharmaceutical solution that is sold in market. The southwestern Brazilian region is the source of the product, specifically the Minas Gerais State. According to Koo et al. (10), there are differences in quality and quantity in chemical compounds of propolis solution collected from different areas. However, this fact does not alter the antifungal activity of the samples.
Flavonoids are well known for their antibacterial, antifungal and antiviral action and are thought to be responsible for the beneficial properties of propolis $(13,15)$. Esters of phenolic acids and specially caffeates and ferulates have also been identified as antibacterial, antifungal and antiviral principles of propolis $(18,26,40)$. This is in good correlation with the action observed from propolis from many countries (20). In the latter, however, the decrease of the phenolic compounds content is not accompained by a decrease of activity. Obviously, there are other compounds that contribute to the biological activity in this case. The triterpenes (lanosterol, cycloarterol, -amyrine and one of its isomers), might play a role, but there could be other active princples, still unidentified. Brazilian prolpolis samples, including those from indigenous bees, contained little or no phenolic acid esters, and most of them contained only traces of flavonoid aglycones. Their activities, however, were similar to those of European samples (20). The large amounts of aromatic (prenylated derivatives of coumaric acid) and diterpenic acids might contribute to the antibacterial activity of these samples $(27,39,41)$.

Some flavonoids are considered antimicrobial, such as pinocembrin, galangin, and sakuranetin $(13,42,43)$. Osawa et al. (44) reported that kaempferol had antimicrobial activity against Strep. mutans and Act. viscosus and Cai and $\mathrm{Wu}(45)$ showed that kaempferol also inhibited the growth of Porph. gingivalis and Prev. intermedia. Aga et al. (41) showed that some hydroxycinnamic acid, isolated and identified in Brazilian propolis, showed antimicrobial activity against Bacillus cereus, Enterobacter aerogenes, and Arthroderma benhamiae.

When the intra-pattern variations of the 12 C. albicans strains from HIV patients were compared, EPE and NYS invariably suppressed the in vitro growth of Candida species. This suggest that NYS and EPE potentiate a fundamental change by inhibiting metabolic precursors involved in $C$. albicans metabolism, even after exposure to the drugs, whereas the other drugs seem to be less potent.

The antifungal activity of CL, EC, FL and NYS observed in the strains collected from HIV-seronegative patients (Table 2) was expected and showed the efficacy of these drugs, even now confirmed in literature (9). However, when these results and those from HIV- seropositive patients are compared, the profile of inhibition was significantly different. However, azoles are usually used in complicated cases of candidiasis when the possibility of using NYS is over (46).

Propolis has been used as a medicine all over the world in a random, indiscriminate manner without medical indication, and is considered to belong to the cosmetic 
group. Thus, there is no systematization or control of its use by the population. The ethanol solution is the form most frequently available in grocery stores, pharmacies and stores specializing in apicultural products. Considering the free access of the population to propolis solutions and the fact that they are natural medicines with no therapeutic contraindication, our study suggest that EPE can be used topically in HIV patients infected by oral candidiasis.

Brazilian propolis has been studied all over the world from different viewpoints $(4,10,47,48)$, nevertheless in vitro results cannot be directly extrapolated to in vivo biological conditions. In vivo studies should be carried out for a better evaluation of the activity of propolis against microorganisms of the Candida species, considering the dynamics of human beings as a whole, as well as the interference of systemic parameters and oral ecology.

\section{Acknowledgments}

The authors are grateful to Néctar Farmaceutica (Belo Horizonte, Brazil), CECON (São Paulo, Brazil), BIOBRÁS (Belo Horizonte, Brazil), and the SIDA Standard Treatment Center (CTR) of the Belo Horizonte City Hall. This work was supported by the National Research Council (CNPq).

\section{References}

1. Samaranayake, L.P. (1990) Host factors and oral candidosis. In Oral candidosis. Saramanayake, L.P. and MacFarlane T.W. eds., Wright, London, 66-80

2. Samaranayake, L.P. and Holmstrup, P. (1989) Oral candidiasis and human immunodeficiency virus infection. J. Oral Pathol. Med. 18, 554-564

3. Feigal, D.W., Katz, M.H., Greenspan, D., Westenhouse, J., Winkelstein, W. Jr., Lang, W., Samuel, M., Buchbinder, S.P., Hessol, N.A., Lifson, A.R. (1991) The prevalence of oral lesions in HIVinfected homosexual and bisexual men: three San Francisco epidemiological cohorts. AIDS 5, 519525

4. Holbrook, W.P. and Kippax, R. (1979) Sensitivity of Candida albicans from patients with chronic oral candidiasis. Postgrad. Med. J. 55, 692-694

5. Samaranayake, L.P. and MacFarlane, T.W. (1981) A retrospective study of patients with recurrent chronic atrophic candidosis. Oral Surg. Oral Med. Oral Pathol. 52, 150-153

6. Montauk, S.L and Mandell, K. (1992) Update on drug therapy for HIV and related infections in adults. Am. Fam. Physician 46, 1772-1781

7. Baily, G.G., Perry, F.M., Denning, D.W. and Mandal, B.K. (1994) Fluconazole-resistant candidosis in an HIV cohort. AIDS 8, 787-792
8. Chavanet, P., Lopez, J., Grappin, M., Bonnin, A., Duong, M., Waldner, A., Buisson, M., Camerlynck, P. and Portier, H. (1994) Cross-sectional study of the susceptibility of Candida isolates to antifungal drugs and in vitro-in vivo correlation in HIV-infected patients. AIDS 8, 945-950

9. Ellepola, A.N. and Samaranayake, L.P. (1998) The effect of limited exposure to antimycotics on the relative cell-surface hydrophobicity and the adhesion of oral Candida albicans to buccal epithelial cells. Arch. Oral Biol. 43, 879- 887

10. Koo, H., Rosalen, P.L., Cury, J.A., Park, Y.K., Ikegaki, M. and Sattler, A. (1999) Effect of Apis mellifera propolis from two Brazilian regions on caries development in desalivated rats. Caries Res. 33, 393-400

11. Thomson, W.McL. (1990) Propolis. Med. J. Austr. 153,654

12. Porkhun, F. T. and Borovaia, A. Ia. (1970) Bactericidal effect of propolis and its use in clinical practice. Voenno-Meditsinskii Zhurnal 9, 65-66 (in Russian)

13. Ghisalberti, E.L. (1979) Propolis: a review. Bee World. 60, 59-84

14. Bankova, V.S., Popov, S.S.and Marekov, N.L. (1989) Isopentenyl cinnamates from poplar buds and propolis. Phytochemistry 28, 871-873

15. Marcucci, M.C. (1995) Propolis: chemical composition, biological properties and therapeutic activity. Apidologie 26, 83-99

16. Lepekhin, V.N. and Leonova, T.A.(1970) Antimicrobial properties of propolis. Stomatologiia 49, 16-19 (in Russian)

17. Bonvehi, J.S., Coll, F.V. and Jordá, R.E. (1994) The composition, active components and bacteriostatic activity of propolis in dietetics. J. Am. Oil Chem. Soc. 71, 529-532

18. Metzner, J., Bekemeier, H., Paintz, M. and Schneidewind, E. (1979) Zur antimicrobiellen Wirksamkeit von Propolis und Propolisinhaltstoffen. Pharmazie 34, 97-102 (in German)

19. Grange, J.M. and Davey, R.W. (1990) Antibacterial properties of propolis (bee glue) J.R. Soc. Med. 83, $159-160$

20. Kujumgiev, A., Tsvetkova, I., Serkedjieva, Y., Bankova, V., Christov, R. and Popov, S. (1999) Antibacterial, antifungal and antiviral activity of propolis of different geographic origin. J. Ethnopharmacol. 64, 235-240

21. Bankova, V., Christov, R., Stoev, G.and Popov, S. (1992) Determination of phenolics from propolis by 
capillary gas chromatography. J. Chromatogr. 607, 150-153

22. Konig, B. (1985) Plant sources of propolis. Bee World 66, 136-139

23. Greenaway, W., Scaysbrook, T. and Whatley, F.R. (1990) The composition and plant origins of propolis: a report of work at Oxford. Bee World 71, 107-118

24. Collins, C.H., Lyne, P.M. and Grange, J.M. (1995) Collins and Lyne's microbiological methods. 7th ed., Butterworth-Heinemann, London, 178-205

25. Hindler, J.A and Jorgensen, J.H. (1995) Procedures in antimicrobial susceptibility testing. In Text book of diagnostic microbiology. Chapter 3, Concepts in antimicrobial therapy, Mahon, C. and Manuselis, G. Jr. eds., W. B. Saunders, London, 63-64

26. Kujumgiev, A., Bankova, V., Ignatova, A. and Popov, S. (1993) Antibacterial activity of propolis, some its components and their analogs. Pharmazie 48, 785786

27. Marcucci, M.C., Ferreres, F., Custodio, A.R., Ferreira, M.M., Bankova, V.S., Garcia- Viguera, C. and Bretz, W.A. (2000) Evaluation of phenolic compounds in Brazilian propolis from different geographic regions. Z. Naturforsch. [C] 55, 76-81

28. Dobrowolski, J.W., Vohora, S.B., Sharma, K., Shah, S.A, Naqvi, S.A.H. and Dandiya P.C. (1991) Antibacterial, antifungal, antiamoebic, antiinflammatory and antipyretic studies on propolis bee products. J. Ethnopharmacol. 35, 77-82

29. Velikova, M., Bankova, V., Marcucci, M.C., Tsvetkova, I. and Kujumgiev, A. (2000) Chemical composition and biological activity of propolis from Brazilian meliponinae. Z. Naturforsch. [C] 55, 785789

30. Barreto, D.C. and Santos, V.R. (1995) Analise do efeito da propolis contra a Candida albicans (Estudo in vitro). Arq. Centro Est. Curso Odontol. Univ. Fed. Minas Gerais 31, 63 (abstract) (in Portuguese)

31. Ellepola, A.N.B. and Samaranayake, L.P. (1998) The effect of limited exposure to antifungal agents on the germ tube formation of oral Candida albicans. J. Oral Pathol. Med. 27, 213-219

32. Amoros, M., Lurton, E., Boustie, J., Girre, L., Sauvager, F. and Cormier, M. (1994) Comparison of the anti-herpes simplex virus activities of propolis and 3-methyl-but-2- enyl caffeate. J. Nat. Prod. 57, 644-647

33. Takaisi-Kikuni, N. B. and Schilcher, H. (1994) Electron microscopic and microcalorimetric investigations of the possible mechanism of the antibacterial action of a defined propolis provenance.
Planta Med. 60, 222-227

34. Marcucci, M.C., Ferreres, F., Garcia-Viguera, C., Bankova, V.S., De Castro, S.L., Dantas, A.P., Valente, P.H. and Paulino, N. (2001) Phenolic compounds from Brazilian propolis with pharmacological activities. J. Ethnopharmacol. 74, 105-112

35. De Paula, A.M.B., Santiago, W.K., Dias, S.M.D., Dias, R.S. and Santos, V.R. (1997) Efeito das soluções de própolis sobre microrganismos patogênicos da cavidade bucal. I. Microrganismos do gênero Candida. Arq. Centro Est. Curso Odontol. Univ. Fed. Minas Gerais 33, 117 (abstract) (in Portuguese)

36. Koo, M.H. and Park, Y.K. (1997) Investigation of flavonoid aglycones in propolis collected by two differents varieties of bees in same region. Biosci. Biotechnol. Biochem. 61, 367-369

37. Park, Y.K., Koo, M.H., Ikegaki, M. and Contado, J.L. (1997) Comparison of the flavonoid aglycone contents of Apis millifera propolis from various regions of Brazil. Arq. Biol. Technol. 40, 97-106

38. Park, Y.K., Koo, M.H., Abreu, J.A., Ikegaki, M., Cury, J.A. and Rosalen, P.L. (1998) Antimicrobial activity of propolis on oral microorganisms. Curr. Microbiol. 36, 24-28

39. Banskota, A.H., Tezuka, Y., Adnyana, I.K., Midorikawa, K., Matsushige, K., Message, D., Huertas, A.A. and Kadota, S. (2000) Cytotoxic, hepatoprotective and free radical scavenging effects of propolis from Brazil, Peru, the Netherlands and China. J. Ethnopharmacol. 72, 239-246

40. Serkedjieva, J., Manolova, N. and Bankova, V. (1992) Anti-influenza virus effect of some propolis constituents and their analogues (esters of substituted cinnamic acids). J. Nat. Prod. 55, 294-302

41. Aga, H., Shibuya, T., Sugimoto, T., Kurimoto, M. and Nakajima, S. (1994) Isolation and identification of antimicrobial compounds in Brazilian propolis. Biosci. Biotechnol. Biochem. 58, 945-946

42. Villanueva, V.R., Bogdanovsky, D., Barbier, M., Gonnet, M., and Lavie, P. (1964) Sur l' identification de la 3,5,7-trihydroxy flavon (galangine): à partir de la propolis. Ann. Inst. Pasteur (Paris) 106, 292302 (in French)

43. Villanueva, V. R., Barbier, M., Gonnet, M. and Lavie, P. (1970) Les flavonoides de la propolis. Isolament d' une nouvelle substance bacteriostatique: la pinocembrine. Ann. Inst. Pasteur (Paris) 118, 8487 (in French)

44. Osawa, K., Yasuda, H., Maruyama, T., Morita, H., Takeya, K., and Itokawa, H. (1992) Isoflavanones 
from the heartwood of Swartzia polyphylla and their antibacterial activity against cariogenic bacteria. Chem. Pharm. Bull. (Tokyo) 40, 29702974

45. Cai, L. and Wu, C.D. (1996) Compounds from Syzygium aromaticum processing growth inhibitory activity against oral pathogens. J. Nat. Prod. 59, 987990

46. Manfredi, R., Mastroianni, A., Coronado, O. V. and Chiodo, F. (1997) Fluconazole as prophylaxis against fungal infection in patients with advanced HIV infection. Arch. Intern. Med. 157, 64-69

47. Bankova, V., Christov, R., Kujumgiev, A., Marcucci, M.C. and Popov, S. (1995) Chemical composition and antibacterial activity of Brazilian propolis. $\mathrm{Z}$. Naturforsch. [C] 50, 167- 172

48. Banskota, A.H., Tezuka, Y., Prasian, J.K., Matsushige, K., Saiki, I. and Kadota, S. (1998) Chemical constituents of Brazilian propolis and their cytotoxic activities. J. Nat. Prod. 61, 896-900 